\title{
A IMPORTÂNCIA DO RECONHECIMENTO DA VULNERABILIDADE DO CONSUMIDOR NA ERA DA OBSOLESCÊNCIA PROGRAMADA
}

\section{THE IMPORTANCE OF RECOGNITION OF CONSUMER VULNERABILITY IN THE TIME OF SCHEDULED OBSOLESCENCE}

\author{
${ }^{1}$ Daniela Ferreira Dias Batista
}

\section{RESUMO}

O presente artigo foi elaborado com o objetivo de favorecer reflexões sobre a necessidade de efetivação do princípio da vulnerabilidade do consumidor, principalmente com a chamada obsolescência programada, prática comum dos fornecedores que disponibilizam no mercado bens com "validades" pré-determinadas unilateralmente, que não guardam qualquer correspondência com sua vida útil real, mas sim com a possibilidade de se tornarem ultrapassados. A importância do tema é evidenciada no dia a dia da atual sociedade em que vivemos, onde o consumo se tornou sinônimo de bem-estar pessoal e social e, nesse cenário, a obsolescência programada aumenta ainda mais o consumo impulsivo e desnecessário.

Palavras-chave: Vulnerabilidade do Consumidor; Proteção Social; Obsolescência Programada.

\begin{abstract}
This article was prepared with the objective of favoring reflections on the need to implement the principle of consumer vulnerability, especially with the so-called programmed obsolescence, a common practice of suppliers that make available on the market goods with unilaterally determined "validities" that do not Correspond with their actual useful life, but with the possibility of becoming outdated. The importance of the theme is evidenced in the day-to-day life of the current society in which we live, where consumption has become synonymous with personal and social well-being, and in this scenario, programmed obsolescence increases even more impulsive and unnecessary consumption.
\end{abstract}

Keywords: Consumer Vulnerability; Social Protection; Programmed Obsolescence.

\footnotetext{
${ }^{1}$ Mestre em Direito pelo Centro Universitário Eurípides de Marília - UNIVEM, São Paulo (Brasil). Professora pelo Centro Universitário Eurípides de Marília - UNIVEM, São Paulo (Brasil). E-mail: danieladbatista@gmail.com
} 


\section{INTRODUÇÃO}

O presente artigo foi elaborado por meio do método de pesquisa analítico teóricoempírico, com o objetivo de provocar reflexões sobre a aplicação e efetivação do princípio da vulnerabilidade do consumidor previsto expressamente no Código de Defesa do Consumidor (CDC), Lei Federal 8.078, de 11 de setembro de 1990, destacando sua importância no contexto atual da sociedade de consumo, em que a obsolescência dos produtos e serviços já vem programada pelo fornecedor desde sua disponibilização no mercado de consumo.

A efetivação das normas de consumo é essencial à concretização do direito fundamental à dignidade humana; nos dias atuais são evidentes os efeitos que o consumo de produtos e serviços provoca no indivíduo e no meio social em que este convive. A sociedade, de forma geral, rotula as pessoas de acordo com os bens que consomem, incluindo-as ou excluindo-as de sua convivência, e, muitas vezes, esse "rótulo" não condiz com a verdadeira realidade econômica e social do indivíduo.

[...] ter e apresentar em público coisas que portam a marca e/ou logo certos e foram obtidas na loja certa é basicamente uma questão de adquirir e manter a posição social que eles detêm ou a que aspiram. A posição social nada significa a menos que tenha sido socialmente reconhecida - ou seja, a menos que a pessoa em questão seja aprovada pelo tipo certo de "sociedade" (cada categoria de posição social tem seus próprios códigos jurídicos e seus próprios juízes) como um membro digno e legítimo - como "um de nós" (BAUMAN, 2009, p. 21).

A sociedade que emergiu das revoluções industrial e tecnológica assenta seu modelo econômico e social na produção e consumo em massa, responsável por uma indisfarçável desindividualização das relações entre consumidor e fornecedor.

A facilidade para comprar os produtos, para contratar serviços e a própria facilitação do crédito (empréstimos, financiamentos, cartão de crédito), fez com que nossa sociedade viva atualmente uma era de compulsão pelo consumo, externando assim, em suas infindáveis variantes, muito do que somos, como nos comportamos e como exercemos a nossa humanidade (qualidades e defeitos) no contexto social.

$\mathrm{Na}$ volatilidade inerente a esses novos tempos, percebemos a predisposição da incessante necessidade que o ser humano tem do novo, deixando claro sua natureza 
insatisfatória, pois, na mesma velocidade em que novos produtos são lançados, são também descartados, se tornando obsoletos, dando lugar a novos produtos, que se tornam objeto de desejo e necessidade em instantes, o que torna o cidadão um ser eternamente insatisfeito se não consumir ativamente.

Os tempos modernos líquidos transformaram a sociedade de trabalhadores em uma sociedade de consumidores, em que o pressuposto básico para a (sobre) vivência é estar apto a consumir. Não existem mais classes de pessoas, nem nacionalidades que nos diferenciam: somos todos consumidores, e a forma como consumimos nos identifica na sociedade. (BAUMAN, 2009, p. 39).

A realidade da exclusão ou inclusão social causada pelo consumismo fica muito bem ilustrada na frase da artista norte-americana, Barbara Krugman, citada em um comentário de economia do sociólogo Joelmir José Beting, que, ao resumir o estado de espírito presente nos tempos atuais, arrisca-se a transformar a famosa máxima da filosofia ocidental "Penso, logo existo", em "Consumo, logo existo". (BETING, 2012, online).

Com o Código de Defesa do Consumidor, surgiu no Brasil uma regulamentação expressa e específica da proteção e defesa do consumidor, que busca primordialmente atingir o equilíbrio nas relações de consumo, protegendo o consumidor vulnerável, para então alcançar a igualdade real das partes envolvidas, garantindo acesso aos produtos e serviços com qualidade e segurança, principalmente àqueles considerados essenciais, buscando por fim, evitar e combater as práticas abusivas para harmonizar os interesses na sociedade de consumo brasileira.

As normas consumeristas trazidas pelo referido estatuto legal são de ordem pública e interesse social (art. $\left.1^{\circ}, \mathrm{CDC}\right)$, caracterizando os direitos do consumidor como indisponíveis e fazendo com que todo ato ou negócio jurídico, contrário às previsões do código, seja considerado nulo de pleno direito, o que demostra claramente a importância social que o legislador deu ao sistema legal consumerista.

A Constituição Federal prevê no seu artigo $5^{\circ}$, XXXII, a defesa do consumidor como garantia e direito fundamental, consequentemente, os direitos previstos no Código de Defesa do Consumidor ou em qualquer outra fonte do direito que verse sobre o assunto, ganham status de direitos fundamentais, protegidos rigorosamente pela Carta Magna brasileira que, 
consequentemente, impõe sua aplicação de ofício para a devida efetivação dos direitos consumeristas.

Sendo assim, não pode o direito do consumidor ser considerado secundário na ciência jurídica, pois este ramo do Direito lida diretamente com o essencial da vida humana, visando garantir os princípios da dignidade humana e o mínimo existencial, este entendido como "o conjunto de garantias materiais para uma vida condigna”. (SARLET, 2007, p. 103).

A efetivação das normas de consumo é essencial à proteção do consumidor, ser vulnerável na sociedade de consumo, em que consumir é sinônimo de inclusão ou exclusão social. Ou seja, o Código de Defesa do Consumidor deve ser observado, cumprido e respeitado para que exista um real equilíbrio na relação jurídica de consumo, principalmente quanto aos seus princípios nessa fase socioeconômica da obsolescência programada, para que o consumidor não fique totalmente "refém" das mazelas do mercado e da própria sociedade de consumo.

\section{PRINCÍPIO DA VULNERABILIDADE DO CONSUMIDOR E A OBSOLESCÊNCIA PROGRAMADA}

O Código Brasileiro de Defesa do Consumidor constitui uma típica norma pósmoderna, pois revisa e revê diversos conceitos antigos do direito privado, como as regras gerais do Direito Civil e Processo Civil, mais especificamente nos elementos e princípios contratuais, na responsabilidade civil, na prescrição e na decadência, entre outros.

Esse enfoque jurídico se tornou necessário por alguns fenômenos pós-modernos que atingiram diretamente as relações de consumo, como a própria globalização, a revolução industrial e a produção massificada em série, a facilitação de pagamento e a tecnologia do mundo moderno.

Diria que a chamada 'pós-modernidade' aparece como uma espécie de Renascimento dos ideais banidos e cassados por nossa modernidade racionalizadora. Esta modernidade teria terminado a partir do momento em que não podemos mais falar da história como algo de unitário e quando morre o mito do Progresso. É a emergência desses ideais que seria responsável por toda uma onda de comportamentos e de atitudes irracionais e desencantados em relação à política e pelo crescimento do ceticismo face 
aos valores fundamentais da modernidade. Estaríamos dando Adeus à modernidade, à Razão (Feyerabend)? Quem acredita ainda que 'todo real é racional e todo racional é real' (Hegel)? Que esperança podemos depositar no projeto da Razão emancipada, quando sabemos que orientou-se para a instrumentalidade e a simples produtividade? Que projeto de felicidade pessoal pode proporcionar-nos um mundo crescentemente racionalizado, calculador e burocratizado, que coloca no centro de tudo o econômico, entendido apenas como o financeiro submetido ao jogo cego do mercado? Como pode o homem ser feliz no interior da lógica do sistema, onde só tem valor o que funciona segundo previsões, onde seus desejos, suas paixões, necessidades e aspirações passam a ser racionalmente administrados e manipulados pela lógica da eficácia econômica que o reduz ao papel de simples consumidor? (JAPIASSU, 2000, online)

O direito à igualdade é inerente à dignidade da pessoa humana, visto que se todas as pessoas por si só são dignas e se todos somos seres humanos, todos somos iguais sem qualquer distinção, porém a desigualdade de condições de algumas pessoas reflete a necessidade de tratamento jurídico desigual para que sua dignidade seja respeitada e garantida.

Com a mitigação do modelo liberal da autonomia da vontade e a massificação dos contratos, percebemos uma discrepância na discussão e aplicação das regras comerciais, o que justifica a presunção de vulnerabilidade, reconhecida como uma condição jurídica, pelo tratamento legal de proteção. (TARTUCE, 2014, p. 43).

O reconhecimento da vulnerabilidade do consumidor é a base, o fundamento da elaboração e da existência das normas jurídicas de consumo. É evidente a preocupação latente do legislador consumerista com a vulnerabilidade do consumidor em relação ao fornecedor e, tendo em vista que o direito à igualdade, às questões de justiça social e à dignidade estão diretamente vinculados à condição vulnerável e até de exclusão do consumidor, é necessário fazermos uma análise do princípio da vulnerabilidade, previsto expressamente no estatuto consumerista.

$\mathrm{Na}$ sociedade atual a desigualdade do consumidor perante o fornecedor é evidente e “essas desigualdades não encontram, nos sistemas jurídicos oriundos do liberalismo, resposta eficiente para a solução de problemas que decorrem da crise de relacionamento e de lesionamentos vários que sofrem os consumidores, pois os Códigos se estruturaram com base em uma noção de paridade entre as partes, de cunho abstrato". (BITTAR FILHO, 2007, p. 2).

O Código de Defesa do Consumidor foi criado com a fundamentação de defender e proteger um segmento de pessoas consideradas vulneráveis, ou seja, o consumidor que, antes 
do surgimento da lei específica, não conseguia proteger efetivamente seus interesses legítimos contra os danos causados pelos fornecedores, tendo em vista a diversidade de condição entre estes.

Sendo assim, prescreve o referido estatuto legal (CDC, 2016 online):

Artigo $4^{\circ}$. A Política Nacional das Relações de Consumo tem por objetivo o atendimento das necessidades dos consumidores, o respeito à sua dignidade, saúde e segurança, a proteção de seus interesses econômicos, a melhoria da sua qualidade de vida, bem como a transparência e harmonia das relações de consumo, atendidos os seguintes princípios:

I - reconhecimento da vulnerabilidade do consumidor no mercado de consumo $(\ldots)$

O reconhecimento da vulnerabilidade do consumidor é uma das medidas essenciais adotadas pelo estatuto consumerista para efetivação da isonomia garantida na Constituição Federal, sendo o princípio básico mais importante para aplicação dos direitos do consumidor, como bem afirma o Superior Tribunal de Justiça:

4. O ponto de partida do CDC é a afirmação do Princípio da Vulnerabilidade do Consumidor, mecanismo que visa a garantir igualdade formal-material aos sujeitos da relação jurídica de consumo, o que não quer dizer compactuar com exageros que, sem utilidade real, obstém o progresso tecnológico, a circulação dos bens de consumo e a própria lucratividade dos negócios. (586316 MG 2003/0161208-5, Relator: Ministro HERMAN BENJAMIN, Data de Julgamento: 17/04/2007, T2 - SEGUNDA TURMA, Data de Publicação: DJe 19/03/2009).

A vulnerabilidade do consumidor, pessoa física e destinatária final de serviços e produtos, deve ser presumida de forma absoluta, sem que seja necessária prova de sua existência (BENJAMIN, 2010).

Quando falamos em consumidor vulnerável significa dizer que este é a parte fraca, mais frágil da relação jurídica de consumo, o que provoca claramente um desequilíbrio, uma desigualdade na relação jurídica e, consequentemente, uma afronta ao princípio constitucional da isonomia que busca uma igualdade substancial, ou seja, real.

A vulnerabilidade do consumidor fica evidente ao verificarmos a soberania dos fornecedores no mercado de consumo, ou seja, o consumidor depende efetivamente do fornecedor para adquirir um produto ou utilizar um serviço, pois é ele que decide quando e como os objetos estarão disponíveis. 
Não é o consumidor que determina o que quer ter acesso no mercado de consumo; o que ocorre, na maioria das vezes, é exatamente o contrário, o fornecedor cria por intermédio de publicidades, sua própria demanda; o consumidor acaba comprando os bens de consumo porque acha que precisa deles e porque eles estão ali disponíveis com preços atrativos e formas de pagamento cada vez mais chamativas.

O Código de Defesa do Consumidor, prevendo a vulnerabilidade do consumidor, busca assegurar a igualdade real entre as partes da relação de consumo, reconhecendo a sempre lembrada, Oração aos Moços, de Rui Barbosa que, inspirado na lição secular de Aristóteles, retrata o direito à igualdade, devendo-se tratar igualmente os iguais e desigualmente os desiguais na medida de suas desigualdades (BARBOSA, 2014, online).

Essa "fraqueza" do consumidor em relação ao fornecedor é real, concreta, e pode ser constatada nos aspectos técnico, jurídico e fático ou socioeconômico.

Em relação ao primeiro aspecto que podemos classificar como vulnerabilidade técnica, o consumidor é a parte mais frágil da relação jurídica por não possuir conhecimentos técnicos, específicos o suficiente, sobre o bem que adquiriu ou o serviço que utilizou, sendo mais facilmente enganado ou ludibriado quanto às características e, até às qualidades daquilo que está consumindo.

A vulnerabilidade técnica está diretamente ligada aos meios de produção, cujo conhecimento é, em regra, monopólio do fornecedor, ou seja, é o fornecedor que escolhe o que, quando e como, produzir um produto ou prestar determinado serviço. Nesse caso, o consumidor não tem poder de decisão ou escolha, ficando à mercê daquilo que é colocado à sua disposição no mercado, até porque nem possui o conhecimento técnico adequado para participar, questionar ou até criticar a atividade do fornecedor.

Já no segundo aspecto, ou seja, a chamada de vulnerabilidade jurídica ou científica, o consumidor é vulnerável por não ter conhecimentos jurídicos suficientes específicos como, por exemplo, conhecer o direito contratual ou normas financeiras para debater em pé de igualdade as cláusulas de um contrato de financiamento de veículo. Isso frequentemente acontece até porque no Brasil infelizmente é público e notório o fato de a maioria da população não conhecer o conteúdo das leis em modo geral, sendo praticamente inexistente o conhecimento dos seus direitos, e, por que não, de seus deveres. 
Por fim, no terceiro e último aspecto, temos a vulnerabilidade fática ou socioeconômica, que "é aquela desproporção fática de forças, intelectuais e econômicas, que caracteriza a relação de consumo" (BENJAMIN, 2010, p. 198), isto é, normalmente o fornecedor possui uma maior capacidade econômica que o consumidor e ainda existem aqueles comentários populares, muitas vezes errôneos, que enfatizam a "perda de tempo" e o insucesso certeiro em litigar com uma grande empresa fornecedora.

A vulnerabilidade social fica evidente na sociedade de consumo em que vivemos atualmente onde frases populares usadas frequentemente em conversas descompromissadas ou postadas em redes sociais como: "dinheiro não é tudo, mas é 100\%", "dinheiro não traz felicidade, mas compra tudo que me leva a ela", revelam a verdadeira preocupação da sociedade em consumir, que para disfarçar o "politicamente incorreto", faz trocadilhos com as palavras criando pseudopiadas.

Exatamente nesse contexto social as pessoas são "classificadas", "rotuladas", reconhecidas ou não como seres sociais "úteis", de acordo com os bens de consumo que possuem, utilizam ou ostentam.

A sociedade de consumo impõe aos seus indivíduos um modo de vida em que não consumir é muito mais que não ser reconhecido socialmente, é simplesmente não existir em sociedade. Por isso, a sociedade de consumidores se revela liquida, ou seja, economicamente valorável e possivelmente vendável, na qual se pode comprar e vender tudo, desde os bens materiais até os bens imateriais, como a moral, o caráter e até a própria inclusão do indivíduo em sociedade, na sociedade líquida as pessoas se tornam as próprias mercadorias.

O filósofo francês Gilles Lipovetsky caracteriza empiricamente a sociedade de consumo por diferentes traços:

Elevação do nível de vida, abundância das mercadorias e dos serviços, culto dos objetos e dos lazeres, moral hedonista e materialista etc. Mas, estruturalmente, é a generalização do processo de moda que a define propriamente. A sociedade centrada na expansão das necessidades é, antes de tudo, aquela que reordena a produção e o consumo de massa sob a lei da obsolescência, da sedução e da diversificação, aquela que faz passar o econômico para a órbita da forma moda. (LIPOVETSKY, 2009, p. 184).

Nesse sentido, temos que a atual sociedade de consumo é aquela que não se importa com as necessidades reais para uma existência digna e sim com a adequação à "moda", ou seja, o que importa é atender aquilo que é imposto pela mídia em geral, pelo mercado de 
consumo e até pela própria sociedade consumista, como sendo o correto, o melhor, o necessário. Assim e somente dessa maneira, o indivíduo é reconhecido como ser existente em sociedade; as necessidades individuais, os valores subjetivos de cada um deixam de ser o necessário, passando a importar somente o que é dito e imposto pela "moda".

Baseado no entendimento de Lipovetsky (2009), podemos dizer que a moda é uma das engrenagens que constituem a sociedade contemporânea, mesmo sendo esse fenômeno, erroneamente visto como um sinônimo para o glamour, o fetiche, a futilidade e a superficialidade. Ao contrário do que prega seu estereótipo geral, a moda interfere constantemente na vida das pessoas, seja nos seus relacionamentos, nas suas atitudes, suas personalidades ou nos seus hábitos cotidianos. Dessa forma, sua função vai muito além desse pensamento pré-definido de moda-fútil. A sociedade segue um círculo consumista e, por existir várias "modas" possíveis, acha que possui uma identidade própria, quando na verdade só está escolhendo dentro daquilo que lhe foi imposto.

Para o sociólogo polonês Zygmunt Bauman (2008) são representações típicas da fragmentação social que vivemos os aspectos como o desejo pela "fama" no sentido de reconhecimento pessoal, pela ascensão pública e o consumo excessivo de produtos e serviços considerados supérfluos, característicos da atual sociedade. Nesta, obrigatoriamente, é necessário se tornar notável, sendo que a propriedade ou a simples utilização de produtos ou serviços considerados ultrapassados, passa a ser vista como sinônimo de estupidez pelos demais indivíduos sociais.

A sociedade de consumidores é uma realidade atual, cada dia mais perceptível e ao mesmo tempo perigosa, pois propõe as pessoas o surgimento incessante de necessidades, com promessas de satisfação pessoal e social, com felicidade garantida a cada nova compra. Essa "promessa" do consumo de uma nova vida ao consumidor, de um reconhecimento e de um renascimento em sociedade, é exatamente o que levam as pessoas a depender de forma tão significativa do consumo de produtos e serviços.

O valor mais característico da sociedade de consumidores, na verdade seu valor supremo, em relação ao qual todos os outros são instados a justificar seu mérito, é uma vida feliz. A sociedade de consumidores talvez seja a única na história humana a prometer felicidade na vida terrena, aqui e agora e a cada "agora" sucessivo. Em suma, uma felicidade instantânea e perpétua. Também é a única sociedade que evita justificar e/ou legitimar qualquer espécie de infelicidade (exceto a dor infligida aos criminosos como "justa recompensa" por seus crimes), que recusa-se a tolerá-la e a apresenta como 
uma abominação que merece punição e compensação. (BAUMAN, 2008, p. $60)$.

É exatamente nesse ponto que a sociedade de consumo se torna "perigosa"; a promessa de felicidade não é uma garantia individual a todos os consumidores, que mesmo comprando o que lhe é oferecido como "felicidade certa", nem sempre alcança o efeito prometido e esperado. Então, frustrado por não conseguir fazer parte dessa sociedade "feliz e perfeita", o consumidor consome mais e mais, de forma irracional e exacerbada, levado pelas pseudonecessidades que lhe foram criadas pela própria sociedade em que vive e da qual quer incansavelmente fazer parte.

O fornecedor, que também faz parte dessa sociedade de consumo, tenta a todo momento fazer uso dessa realidade ao seu favor, o que fica muito mais fácil, pois ele detém os poderes da criação, da fabricação e da disponibilização desses bens de consumo no mercado. O consumidor ainda acredita que ele tem o poder de escolher o que, quando e como compra, mas na verdade os fornecedores pré-determinam o que vai para o mercado de consumo e os consumidores só escolhem dentre aqueles produtos ou serviços que os fornecedores querem disponibilizar.

É nesse contexto social que a obsolescência programada ou planejada e, por alguns até chamada de "garantida", ganha um reflexo muito perigoso para o consumidor, pois como a sociedade lhe impõe contratar e comprar sempre o melhor, o mais moderno, o na moda ou o mais novo, cada vez mais o consumidor fica à mercê do fornecedor, o que consequentemente aumenta em demasia um consumo desnecessário e muitas vezes até inconsciente.

Entre as maneiras com que o consumidor enfrenta a insatisfação, a principal é descartar os objetos que a causam. A sociedade de consumidores desvaloriza a durabilidade, igualando "velho" a "defasado", impróprio para continuar sendo utilizado e destinado à lata de lixo. É pela alta taxa de desperdício, e pela decrescente distância temporal entre o brotar e o murchar do desejo, que o fetichismo da subjetividade se mantém vivo e digno de crédito, apesar de interminável série de desapontamentos que ele causa. A sociedade de consumidores é impensável sem uma florescente indústria de remoção do lixo. Não se espera dos consumidores que jurem lealdade aos objetos que obtêm com a intenção de consumir. (BAUMAN, 2008, p.31).

A obsolescência programada trata-se de uma estratégia dos fornecedores de produtos e serviços que programam o tempo de vida útil de seus produtos e a utilidade eficaz de seus serviços para que durem menos do que a tecnologia ou o próprio uso permite naturalmente. 
Assim, os bens de consumo se tornam ultrapassados, velhos, obsoletos em pouco tempo, motivando o consumidor a comprar um novo modelo para se adequar à sociedade de consumo.

Na técnica da obsolescência programada, os produtos e os serviços, mesmo que ainda desenvolvam suas capacidades e características normalmente, não "servem" mais para o mercado de consumo, pois não geram mais lucro para o fornecedor e não compensa financeiramente ficar consertando vícios ou defeitos de produtos e serviços antigos, quando há muito mais lucro na venda de novos.

A sociedade de consumo acaba por classificar seus indivíduos pelos bens materiais que possuem ou utilizam, exigindo do consumidor que adquira sempre o último lançamento de um celular, de uma televisão ou um carro, por exemplo, para poder ser "melhor" ou simplesmente "igual", aos demais indivíduos sociais, o que demonstra claramente sua condição de vulnerável perante o fornecedor.

Segundo Serge Latouche (2012, p.30):

São necessários três ingredientes para que a sociedade de consumo possa prosseguir o seu circuito diabólico: a publicidade, que cria o desejo de consumidor, o crédito, que lhe fornece os meios, e a obsolescência acelerada e programada dos produtos que, renova a sua necessidade.

A obsolescência programada não deve ser confundida com o período de garantia ou de vida útil dos produtos e serviços oferecidos pelos fornecedores, mas sim pelo fato de termos a cada dia um novo produto/serviço ou até mesmo uma nova tecnologia sendo colocada no mercado de consumo como novidade, assim, aquele produto ou serviço anteriormente comercializado se torna obsoleto, velho ou ultrapassado.

É o que ocorre com frequência nos aparelhos tecnológicos e nos veículos, quando um é disponibilizado para compra no mercado, outro já é anunciado para o próximo ano ou um novo modelo. O consumidor compra o produto sabendo que, no próximo ano, ele já será ultrapassado ou obsoleto; com isso ele já se prepara para comprar o mais novo ou mais atual, sem se preocupar se aquele que já possui ainda tem utilidade, do contrário ele não fará parte da sociedade de consumo que lhe "impõe" o mais moderno, o mais atual, o mais novo, para que exista ativamente em sociedade.

No documentário "Comprar, tirar, comprar - La historia secreta de la obsolescência programada", produzido em 2011, na Espanha, e dirigido por Cosima Dannoritzer, o exemplo 
do cartel organizado por grandes empresas que produziam lâmpadas revelou a obsolescência programada. Os fornecedores de lâmpadas se organizaram para reduzirem o tempo de vida útil de seus produtos a fim de aumentarem as vendas. Sabe-se que a primeira lâmpada inventada durou cerca de 1.500 horas; no início do século XX, as lâmpadas tinham uma vida útil média de 2.500. Entretanto, após a Grande Depressão e a formação do cartel, o tempo de vida útil foi reduzido abruptamente para 1.000 horas. (COMPRAR, 2011, online).

Mais atual, temos o exemplo o exemplo da jurisprudência do Tribunal Superior de Justiça que vem corroborando no sentido de proteger o consumidor da obsolescência programada:

DIREITO DO CONSUMIDOR E PROCESSUAL CIVIL. RECURSO ESPECIAL. AÇÃO E RECONVENÇÃO. JULGAMENTO REALIZADO POR UMA ÚNICA SENTENÇA. RECURSO DE APELAÇ̃̃O NÃO CONHECIDO EM PARTE. EXIGÊNCIA DE DUPLO PREPARO. LEGISLAÇÃO LOCAL. INCIDÊNCIA DA SÚMULA N. 280/STF. AÇÃO DE COBRANÇA AJUIZADA PELO FORNECEDOR. VÍCIO DO PRODUTO. MANIFESTAÇÃO FORA DO PRAZO DE GARANTIA. VÍCIO OCULTO RELATIVO À FABRICAÇÃO. CONSTATAÇÃO PELAS INSTÂNCIAS ORDINÁRIAS. RESPONSABILIDADE DO FORNECEDOR. DOUTRINA E JURISPRUDENCIA. EXEGESE DO ART. 26, $\$ 3^{o}$, DO CDC. (...) 7. Cuidando-se de vício aparente, é certo que o consumidor deve exigir a reparação no prazo de noventa dias, em se tratando de produtos duráveis, iniciando a contagem a partir da entrega efetiva do bem e não fluindo o citado prazo durante a garantia contratual. Porém, conforme assevera a doutrina consumerista, o Código de Defesa do Consumidor, no $\S 3^{\circ}$ do art. 26, no que concerne à disciplina do vício oculto, adotou o critério da vida útil do bem, e não o critério da garantia, podendo o fornecedor se responsabilizar pelo vício em um espaço largo de tempo, mesmo depois de expirada a garantia contratual. 8. Com efeito, em se tratando de vício oculto não decorrente do desgaste natural gerado pela fruição ordinária do produto, mas da própria fabricação, e relativo a projeto, cálculo estrutural, resistência de materiais, entre outros, o prazo para reclamar pela reparação se inicia no momento em que ficar evidenciado o defeito, não obstante tenha isso ocorrido depois de expirado o prazo contratual de garantia, devendo ter-se sempre em vista o critério da vida útil do bem. 9. Ademais, independentemente de prazo contratual de garantia, a venda de um bem tido por durável com vida útil inferior àquela que legitimamente se esperava, além de configurar um defeito de adequação (art. 18 do CDC), evidencia uma quebra da boa-fé objetiva, que deve nortear as relações contratuais, seja de consumo, seja de direito comum. Constitui, em outras palavras, descumprimento do dever de informação e a não realização do próprio objeto do contrato, que era a compra de um bem cujo ciclo vital se esperava, de forma legítima e razoável, fosse mais longo. 10. Recurso especial conhecido em parte e, na extensão, não provido. 
(STJ - Recurso Especial no 984.106 - SC 2007/0207915 - Relator: Ministro

Luis Felipe Salomão). (grifo nosso)

O relator Ministro Luis Felipe Salomão ainda ressalta:

6.2. Ressalte-se, também, que desde a década de 20 - e hoje, mais do que nunca, em razão de uma sociedade massificada e consumista -, tem-se falado em obsolescência programada, consistente na redução artificial da durabilidade de produtos ou do ciclo de vida de seus componentes, para que seja forçada a recompra prematura.

Nessas circunstâncias, é até intuitivo imaginar que haverá grande estímulo para que o produtor eleja estratégias aptas a que os consumidores se antecipem na compra de um novo produto, sobretudo em um ambiente em que a eficiência mercadológica não é ideal, dada a imperfeita concorrência e o abuso do poder econômico, e é exatamente esse o cenário propício para a chamada obsolescência programada (STJ - Recurso Especial no 984.106 SC 2007/0207915 - Relator: Ministro Luis Felipe Salomão, Documento: 1182088 - Inteiro Teor do Acórdão, p. 17).

$\mathrm{Na}$ atualidade, temos vários exemplos da obsolescência programada quando falamos de produtos eletroeletrônicos como, por exemplo, os celulares, sendo que os fornecedores lançam o modelo, já anunciando o próximo, com novas funções, mais capacidade para aplicativos e tecnologias "super" modernas, criando no consumidor a expectativa de já se preparar para a nova compra, quando ainda nem conseguiu pagar a que acabou de realizar.

O mais estranho é que, de um lançamento para o outro mais novo, temos um lapso temporal de um ano ou até de poucos meses, o que não justifica a novidade por conclusão de pesquisas ou criação tecnológicas, pois o tempo não é hábil para tamanha dificuldade técnica e cientifica. Assim, mais uma vez, por sua latente vulnerabilidade, o consumidor fica alheio aos mandos e desmandos dos fornecedores que monopolizam as informações essenciais e verídicas sobre a real durabilidade de seus produtos e sobre a eficácia no tempo dos seus serviços.

A música, dentre outras formas de arte, sempre foi e será, uma forma para a sociedade expressar seus sentimentos e pretensão favoráveis ou contrários a determinados fenômenos, eventos ou momentos sociais e econômicos. Por isso, é interessante trazermos a letra da música $3^{\text {a }}$ do Plural, da banda de grande sucesso no Brasil, Engenheiros do Havaii (LETRAS, 2016, online, grifo nosso):

Corrida pra vender cigarro

Cigarro pra vender remédio 


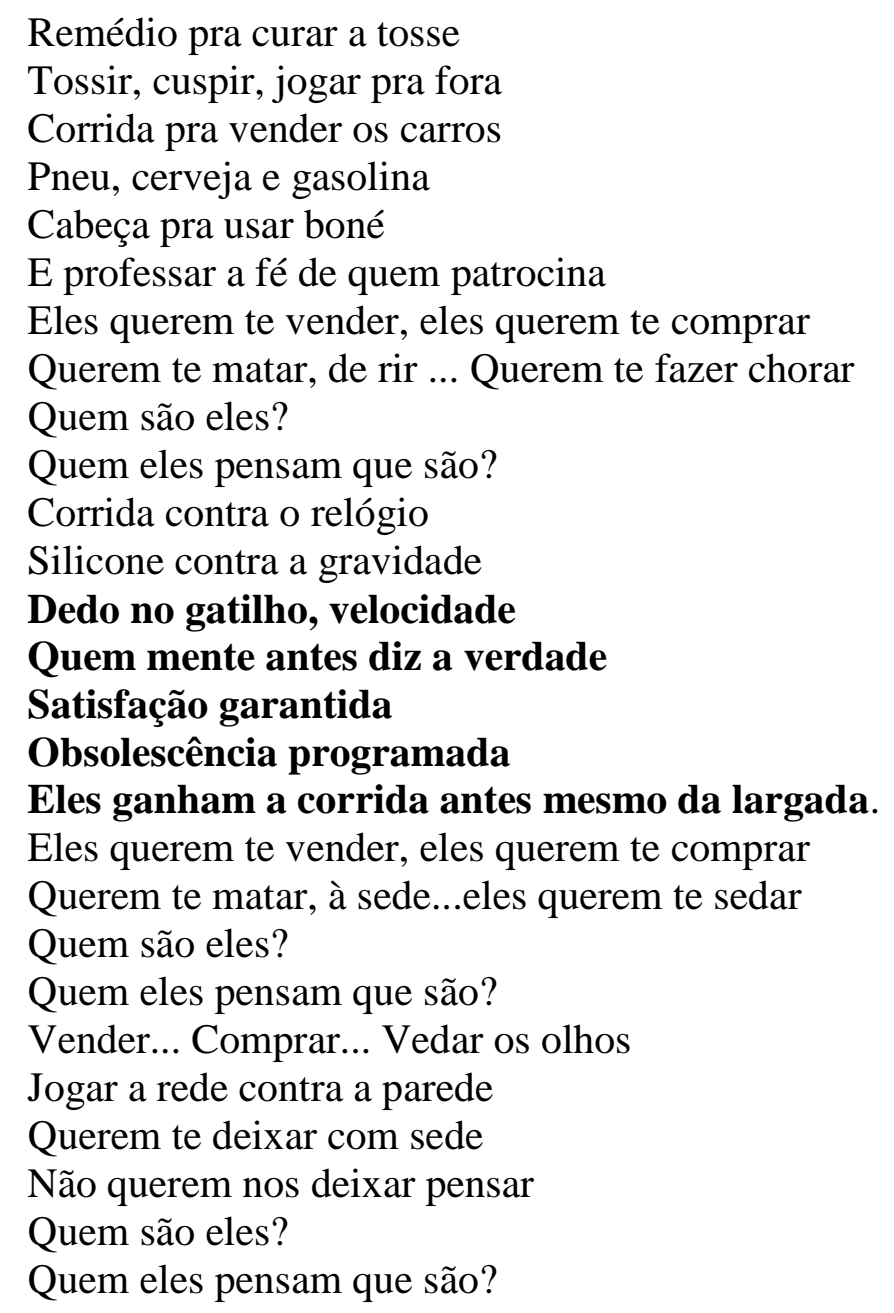

A letra da música, mesmo com todos os possíveis "erros" da licença poética, reflete exatamente a necessidade do reconhecimento da vulnerabilidade desse consumidor, que é alvo incessante do fornecedor, que impõe, dentre outras, mediante a obsolescência programada, uma corrida perdida pelo consumidor desde a largada (projeto e fabricação do produto). Isso deixa evidente a soberania do fornecedor perante o consumidor que sequer entende o que está acontecendo, ou seja, ele realmente acredita que precisa comprar o mais atual, o mais rápido possível, para só então ter sua "satisfação garantida".

O consumidor é um fantoche do fornecedor, que desde a fabricação até a comercialização e descarte do seu produto, manipula seus clientes, induzindo e, muitas vezes, socialmente impondo, o que, como, quando e quantos comprar, não tendo o consumidor como sair desse círculo que, na maioria das vezes, se torna um grande vício imperceptível para o próprio indivíduo. 
Por todo o exposto, podemos concluir que a vulnerabilidade do consumidor é o grande fundamento da proteção consumerista, visto que busca garantir a igualdade entre as partes, para que a relação jurídica de consumo seja equilibrada a ponto de satisfazer os anseios da sociedade consumista, sem prejudicar a livre iniciativa econômica, necessária ao desenvolvimento socioeconômico do país.

Com base na vulnerabilidade do consumidor, o legislador consumerista prevê direitos próprios ao consumidor para que este não fique totalmente à mercê dos devaneios e manipulações do mercado de consumo, que muitas vezes criam "pseudas necessidades" aos consumidores que acabam sucumbidos por promessas de felicidade plena e realização pessoal e social.

A proteção desigual estabelecida pelo Código de Defesa do Consumidor é instrumento necessário para atingir a igualdade pretendida pelo princípio constitucional, visto que o consumidor é presumidamente a parte mais fraca da relação jurídica e depende de proteção excepcional para alcançar a real igualdade.

\section{CONSIDERAÇOES FINAIS}

O presente artigo demonstra como o reconhecimento da vulnerabilidade do consumidor, no atual contexto da obsolescência programada, é essencial e claramente necessário para a proteção social do consumidor vulnerável, principalmente na sociedade consumista em que vivemos atualmente.

Quando falamos em exclusão social, a primeira necessidade latente que surge na tentativa de abolir tal fenômeno é exatamente a proteção do vulnerável, a efetivação mais abrangente possível da igualdade social para a concretização da dignidade da pessoa humana que necessita viver em sociedade.

O Código de Defesa do Consumidor, Lei Federal 8.078/90, principiológica, de ordem pública e interesse social, se mostra corolário com o princípio constitucional da igualdade e da dignidade da pessoa humana expressos na Constituição Federal Brasileira, pois busca incansavelmente o equilíbrio da relação jurídica de consumo protegendo o consumidor, considerado vulnerável de forma socioeconômica, técnica ou jurídica, e garantindo a todos o acesso com qualidade e segurança aos produtos e serviços disponíveis no mercado de 
consumo, que acabam refletindo, positiva ou negativamente, na existência digna do ser humano em sociedade.

$\mathrm{O}$ respeito à dignidade da pessoa humana fica evidenciado, principalmente, pelo reconhecimento legal e presumido da vulnerabilidade do consumidor em relação ao fornecedor, exigindo um tratamento especial e diferenciado, trazido ao consumidor pelo estatuto consumerista, que destaca nos seus princípios a vulnerabilidade do consumidor, parte mais "fraca" na relação jurídica de consumo, assim, também, observando o princípio constitucional da igualdade, em que a lei deve tratar desigualmente os desiguais na medida de suas desigualdades para então, garantir a igualdade real, concreta entre as partes.

A necessidade de consumir para existir socialmente acaba marginalizando aqueles que não estão dentro dos padrões aceitos pela maioria como corretos ou normais; são eles, que não possuem nem uma boa condição financeira para arcar com suas dívidas essenciais, que são impulsionados por esse consumismo social e acabam na tomada injusta de créditos com juros e taxas absurdas, levando cada vez mais a uma condição ainda mais vulnerável e mais excluída.

O principal desafio da proteção e defesa do consumidor contemporâneo não é tão somente a distribuição correta das obrigações e dos direitos do fornecedor e do consumidor, mas sim a conscientização deste último, quanto à necessidade da aquisição de produtos e serviços, muitas vezes supérfluos, de forma exacerbada, desvirtuando a característica de direito humano e fundamental da proteção consumerista, por isso tamanha a importância desse instituto jurídico na proteção social.

A obsolescência programada muitas vezes cria no consumidor essa necessidade irreal de consumir mais do que o necessário e, talvez pior, consumir produtos considerados supérfluos que não estão vinculados diretamente a sua saúde, moradia, educação e alimentação, o que consequentemente descaracteriza o consumo consciente, elevando consideravelmente o consumo impulsivo e o aumento do endividamento do consumidor.

O endividamento (superendividamento) do consumidor brasileiro está cada dia mais evidente nas manchetes dos mais variados e populares meios de comunicação, que indica o aumento dos índices de inclusão nos órgãos de proteção ao crédito (SPC Brasil e SERASA), o que demonstra claramente a grande influência que o consumo impulsivo e inconsciente pode causar no cidadão e, por fim, na própria sociedade como um todo. 
Com a devida aplicação princípio da vulnerabilidade, esperamos o efetivo reconhecimento do consumidor como a parte mais fraca da relação jurídica de consumo, principalmente pelas influências da sociedade de consumo atual e pelas manobras do mercado de consumo que não respeitam a real necessidade dos consumidores. Ávidos por mais lucro, esse mercado acaba criando um "fim" para seus produtos e serviços que não correspondem com o desgaste natural ocasionado durante a vida útil real dos bens de consumo, prejudicando a sociedade em geral, mas principalmente os grupos sociais menos favorecidos e marginalizados, que não possuem conhecimento ou discernimento suficientes para não se tornarem vítimas desse sistema.

\section{BIBLIOGRAFIA}

BARBOSA, Rui. Oração aos moços. Disponível em: http://www.casaruibarbosa.gov.br/dados/DOC/artigos/rui_barbosa/FCRB_RuiBarbosa_Oraca o_aos_mocos.pdf. Acesso em: 02 mar. 2014.

BAUDRILLARD, Jean. A sociedade de consumo. Tradução Artur Morão. Lisboa/Portugal: Edições 70, 2007.

BAUMAN, Zygmunt. Modernidade líquida. Tradução Plinio Dentzien. Rio de Janeiro: Jorge Zahar Ed., 2009.

Vida para Consumo: a transformação das pessoas em mercadorias. Tradução Carlos Alberto Medeiros. Rio de Janeiro: Jorge Zahar Ed., 2008.

Globalização: as consequências humanas. Tradução Marcus Penchel. Rio de Janeiro: Jorge Zahar Ed., 1999.

BENJAMIN, Antônio Herman V. [et al]. Manual de Direito do Consumidor. 3. ed. atual. e ampl. São Paulo: Editora Revista dos Tribunais, 2010.

BETING, Joelmir. Análise do dia. Traduzindo o economês. Eu consumo; logo, existo. Disponível em: http://www.joelmirbeting.com.br/noticias.aspx?IDgNews=2\& IdNews=3265. Acesso em: 18 jul. 2016.

BITTAR FILHO, Carlos Alberto. Direitos do consumidor: dano moral e cláusulas abusivas. 2.ed. São Paulo: IOB Thomson, 2007.

BRASIL. Constituição da República Federativa do Brasil de 1988. Disponível em: http://www.planalto.gov. br/ ccivil_03/constituicao/constitui\%C3\%A7ao.htm. Acesso em: 10 jul. 2016. 
CADERNO de Investigações Científicas. Prevenção e Tratamento do Superendividamento/Escola Nacional de Defesa do Consumidor; elaboração Professora Cláudia Lima Marques e juízas Clarissa Costa de Lima e Káren Bertoncello - Brasília: SDE/DPDC, 2010, Volume 1. Disponível em: http://portal.mj.gov.br/dpdc/ main.asp?Team. Acesso em: 14 jul. 2016.

CDC - Código de Defesa do Consumidor. Lei 8.078 de 11 de setembro de 1990. Disponível em: http://www.planalto.gov.br/ccivil_03/leis/18078compilado.htm. Acesso em: 20 jul. 2016.

COMPRAR, Comprar, tirar - La historia secreta de la obsolescência programada. Documentário. Produção Espanhol. Direção: Cosima Dannoritzer, 2011. Disponível com tradução em: https://www.youtube.com/watch?v=h30xIxtDzl8. Acesso em 13 ago. 2016.

FEDERAÇÃO do Comércio de Bens, Serviços e Turismo do Estado de São Paulo (Fecomercio). Radiografia do Endividamento das Famílias Brasileiras. Junho de 2014.http://www.fecomercioes.com.br/assetmanager/assets/Radiografia\%20do\%20Endividam ento\%20das\%20Fam\%C3\%ADlias\%20-\%202014.pdf. Acesso em: 20 nov. 2014.

GRINOVER, Ada Pellegrini [et al]. Código Brasileiro de Defesa do Consumidor: comentado pelos autores do anteprojeto. 10. ed. rev., atualiz. e reform. Rio de Janeiro: Forense, 2011, vol. I. Direito Material (arts. $1^{\circ}$ a 80 e 105 a 108).

JAPIASSU, Hilton Ferreira. A crise da razão no ocidente. Editora Eletrônica, 2000. Disponível em: <http://www.sinergiaspe.net/editoraeletronica/autor/069/06900100.htm>. Acesso em: 17 mar. 2016.

KANT, Immanuel. Fundamentação da Metafísica dos Costumes e Outros Escritos. Tradução Leopoldo Holzbach. São Paulo: Martin Claret, 2004.

KELSEN, Hans, 1881-1973. O problema da justiça. Tradução de João Baptista Machado. 5. ed. São Paulo: Martins Fontes, 2011.

Teoria Pura do Direito. Tradução João Baptista Machado. 6. ed. São Paulo: Editora Martins Fontes, 1998.

LATOUCHE, Serge. O pequeno tratado do decrescimento sereno. Reimp. Lisboa: Edições 70, 2012.

LIPOVETSKY, Gilles. O império do efêmero: a moda e seu destino nas sociedades modernas. Tradução Maria Lucia Machado. São Paulo: Companhia das Letras, 2009.

Barcarolla, 2004.

Os tempos hipermodernos. Tradução Mário Vilela. São Paulo: Editora 
MARQUES, Claudia Lima [et al]. Consumo como igualdade e inclusão social: a necessidade de uma lei especial para prevenir e tratar o "superendividamento" dos consumidores pessoas físicas. Revista Jurídica da Presidência/Presidência da República. Centro de Estudos Jurídicos da Presidência - Vol. 1, n. 1, maio. Quadrimestral. Brasília: Centro de Estudos Jurídicos da Presidência, 1999.

LETRAS, de músicas. $\mathbf{3}^{\text {a }}$ do Plural. Engenheiros do Hawaii. Disponivel em: https://www.letras.mus.br/engenheiros-do-hawaii/747530/. Acesso em 20 de set. 2016.

SANDEL, Michael J. Justiça - o que é fazer a coisa certa. Tradução de Heloisa Matias e Maria Alice Máximo. 9. ed. Rio de Janeiro: Civilização Brasileira, 2012 (a).

O que o dinheiro não compra: os limites morais do mercado. Tradução de Clóvis Marques. Rio de Janeiro: Civilização Brasileira, 2012 (b).

SARLET, Ingo Wolfgang. Direitos fundamentais sociais, mínimo existencial e direito privado. Revista de Direito do Consumidor. Vol. 61. 2007.

SERASA Experian. Indicadores Econômicos. Inadimplência do Consumidor. Disponível em: http://www.serasaexperian.com.br/release/indicadores/inadimplencia_consumidor.htm. Acesso em: 25 jun. 2016.

TARTUCE, Flávio. [et al]. Manual de direito do consumidor: direito material e processual. 3. ed. São Paulo: MÉTODO, 2014. 